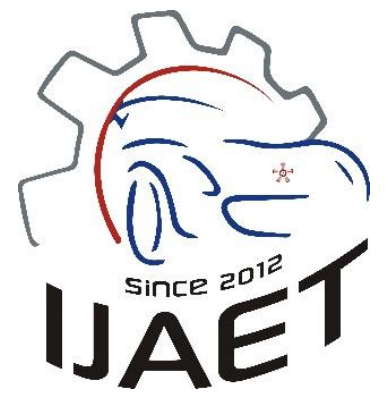

e-ISSN: 2146 - 9067

International Journal of Automotive

Engineering and Technologies

journal homepage:

https://dergipark.org.tr/en/pub/ijaet

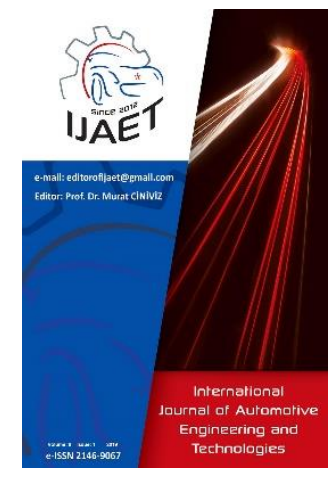

Original Research Article

\title{
Investigation of the usability of MWCNTs Filled GFR/Aluminum honeycomb sandwich composites for automotive vehicles
}

\section{Mehmet Turan Demirci ${ }^{1}$ *}

1, *Selçuk University, Department of Metallurgical and Materials Engineering, Konya, Turkey

\section{ARTICLE INFO}

1 0000-0003-1941-9277

* Corresponding author

turandemirci@selcuk.edu.tr

Received: May 14, 2020

Accepted: June 25, 2020

Published by Editorial Board Members of IJAET

(C) This article is distributed by Turk Journal Park System under the CC 4.0 terms and conditions.

\begin{abstract}
In order to provide fuel saving and performance in gasoline/diesel automotive vehicles, and to increase the long range of the electric battery in electric vehicles, lightening studies in the weight of automotive vehicles are carried out by researchers at the automotive $\mathrm{R} \& \mathrm{D}$ (Research and Development) centers in the university and industry. The reducing of weight of automotive vehicles finds out some problems such as low crashworthiness and safety. These highlight problems bring something into the forefront the use of ultra-light honeycomb sandwich composites having high mechanical properties in the automotive industry. In addition, the mechanical properties of fiber-reinforced honeycomb sandwich composites can be further improved by limiting the formation of damages during impact by using nanotechnology. In this study, the usability of multi walled nanoparticles (MWCNTs) filled and unfilled GFR/Aluminum honeycomb sandwich composites instead of metal protection bars in the doors of automotive vehicles was investigated. It was found that $0.3 \%$ wt MWCNTs increased the average maximum bending loads, displacements and impact energy absorptions by about $2.1,1.36$ and 1.5 times respectively according to compared to unfilled GFR/Aluminum honeycomb sandwich composites. The slip-stick failure mechanism was observed at interfaces of unfilled GFR composite face sheets and aluminum honeycomb core. The delamination failures were found as dominant failure as result of poor adhesion for them. It was detected with microscope and SEM analysis that MWCNTs restricted the occurrence of failures during the bending load and impact. MWCNTs provided the fillet occurrence at interfaces by increasing the contact bonding areas. Plastic deformation was found as dominant failure for them. It is thought that the crashworthiness and safety can be improved by using MWCNTs filled GFR/aluminum honeycomb sandwich composites in car doors instead of metal protection bars.
\end{abstract}

Keywords: Crashworthiness, Impact Energies, Automotive Vehicles, MWCNTs, Honeycomb Sandwich Composites.

\section{Introduction}

The troubles of energy due to the scarcity of fossil fuels and environmental pollution that may occur in the next century when make it necessary to provide energy efficiency and reduce the emission in cars. Nowadays, in 
order to ensure the effective performance and fuel saving of the cars, researches are making many studies to design the modern cars of the age. As a result of the researches, it was revealed that the biggest factor affecting the performance of the cars and the consumption of gasoline/diesel fuel was the weight problem [1]. This weight problem is becoming more and more important not only in gasoline/diesel fuel savings, but also in batteries of electric cars for the automotive future. Ultra lightening studies in electric cars aim to increase the electric battery life, range of long distance and high efficiency performance by reducing the load on electric motors. Composites used in the parts and structures of gasoline/diesel fuel and electric vehicles for weight reduction design and manufacture of them show superior properties compare to metal based materials such as aluminum and steels. These superior properties of composites are high impact energy absorption, high corrosive resistance, and high strength performance to lightweight, high crashworthiness. Composites used in both gasoline/diesel fuel vehicles and lightening works in the body structures and parts of electric vehicles show superior specific properties compared to metal based materials such as aluminum and steel [2, 3]. Thus, energy savings and high speed performance have been obtained by reducing the weight of the vehicles with the composites. Wang et al. (2018) stated in their study that the body of the Lamborghini Murciélago vehicle was produced entirely from carbon fiber composite, and the car's weight was reduced by $145.5 \mathrm{~kg}$, and the body structure had high strength [4]. However, it needs innovations in composite materials and usage areas due to advancing technology and increasing costs. These innovations include ultra-lightening in the weights of automotive vehicles. These innovations are important not only for automotive vehicles but also for marine, air vehicles etc. [5-10]. Recently, the studies on fiber-reinforced honeycomb sandwich composite structures meet these innovations that are required for vehicles.

The features of fiber reinforced honeycomb composite sandwich structures like that the high mechanical performance/weight ratio, high chemical resistance, high structural rigidity and bending resistance and especially excellent impact energy absorption and load capacity might promise a bright future for the usage of these materials in the automobile vehicle industry. Weight lightening with composites has increased to ultra-lightening level with fiber-reinforced honeycomb sandwich composites by providing high energy absorption and the high crashworthiness besides with efficient fuel cost/energy performance and low fuel cost [1,2,4,11-18]. When the literature is investigated in detail, it can be thought that fiber-reinforced honeycomb composite structures can be effective in providing safety against crashes in vehicles for driver and passenger.

Zhang et al. (2017) stated that carbon fiber reinforced (CFRP) honeycomb composite structures have been started to be used in the body of BMW i3 electric car (electric automotive vehicles) as shown in Figure 1. And their improvement studies and tests have been continued in honeycomb composite structures. They pointed out in these tests that it was aimed to increase the road distance of the electric car by reducing the weight of the electric car and to increase the strength and impact energy absorption in the main body structure of the electric car [19].

Sandwich composite structures generally consist of top and bottom face sheets, interface adhesive and core structures being different forms but generally hexagonal form. The top and bottom face sheets of honeycomb sandwich composites can consist of aluminum and carbon, glass etc. fiber-reinforced composite plates. The honeycomb core material could be polyurethane foam, aramid and aluminum honeycomb core structures. This material of honeycomb core can change according to the preference of usage area in order to provide high stiffness, corrosion and fatigue resistance and bending strength to ultralight weight. The schematic view of fiber reinforced honeycomb sandwich composite is presented in Figure 2. [10, 11, 16, 17, 20-23, 27].

In general aramid and aluminum honeycomb core structures are used in order to obtain high strength in sandwich composite structures. The studies of researches related in the properties of 


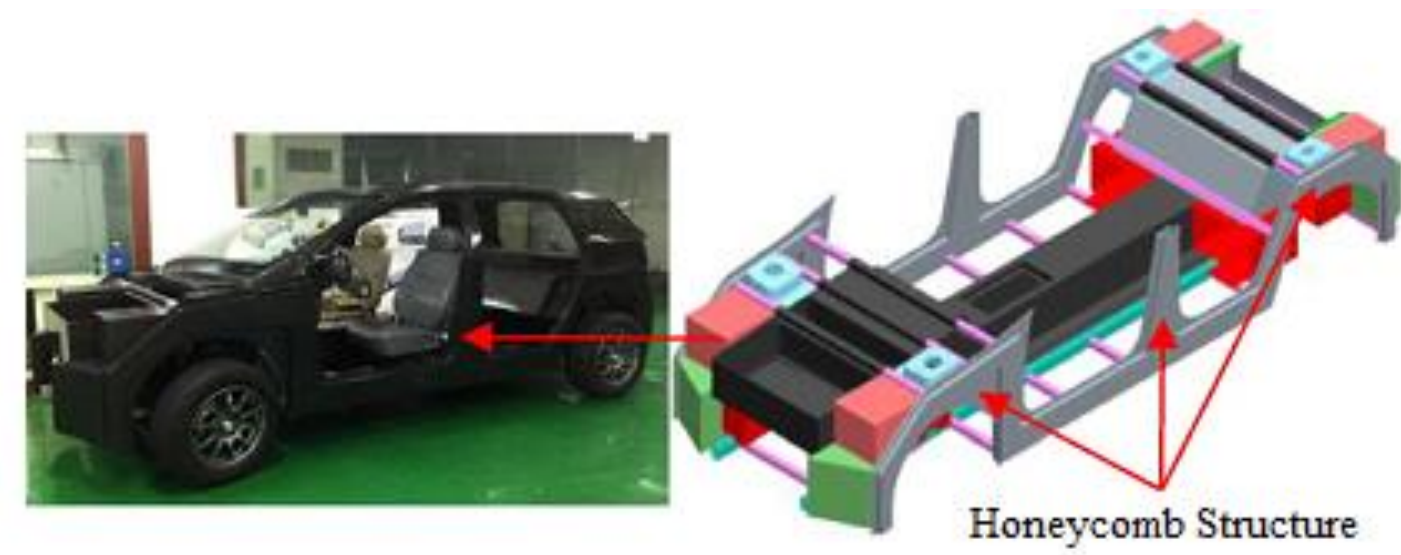

Figure 1. Fiber reinforced honeycomb sandwich composite structure of BMW i3 [19].
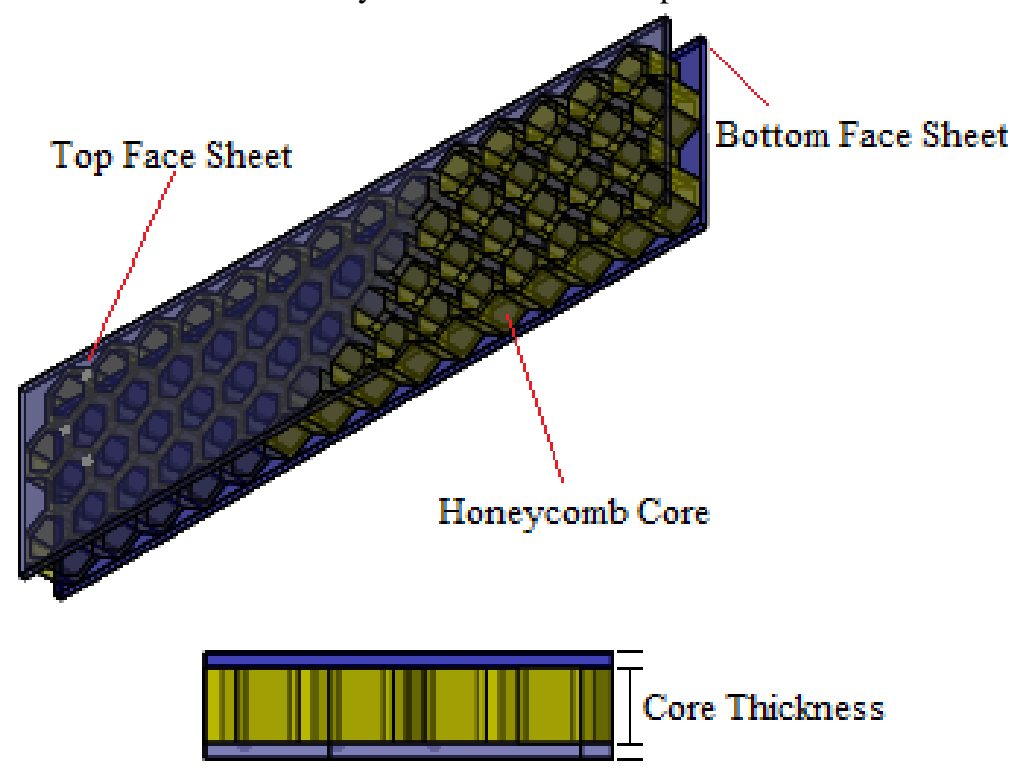

Figure 2. Schematic view of fiber reinforced honeycomb sandwich composite.

fiber reinforced aluminum honeycomb sandwich composites such as the effective performances with ultra-lighting for fuel/electric battery life and speed, high load carrying capacity, high impact energy absorption, crash protection, crashworthiness and low cost with aluminum honeycomb core plays the effective role for the usage in automotive vehicle industry [24-26].

Many researchers lead to carry out the studies due to the feature of high impact shock absorption of fiber-reinforced honeycomb composite sandwich structures which are an important key for vehicles. In their studies, they applied to tests of static compression, low velocity and Charpy impact and four and three point bending in order to determine the amount of bending strength and displacement, compression strength and displacement, crashworthiness and absorbed impact energies in aluminum honeycomb sandwich composites.
Wang et.al. (2018) carried out the studies on the use of carbon fiber reinforced aluminum honeycomb composites due to their superior performance, in the automotive industry. They examined the effects of changing thickness of aluminum honeycomb thicknesses by applying three-point bending and peeling tests. They stated that as the thickness of the core of honeycomb affected ultimate loads increase. In addition, they determined that the similar failures at the interfaces of the carbon fiber reinforced laminated composite face sheets and aluminum honeycomb core and deformation of aluminum honeycomb core were observed in each thickness of aluminum honeycomb core. The failures that occurred in specimens were found as independent of core thickness [4]. Flasar et. al. (2017) studied the different stacking sequence of the cross ply [0/90] and angle-ply $[ \pm 45]$ laminated carbon fiber reinforced aluminum honeycomb sandwich 
composites by applying Charpy impact tests. While they obtained the best energy absorption in angle-ply [ \pm 45$]$ laminated carbon fiber reinforced aluminum honeycomb sandwich composites, they found the highest load in the cross ply [0/90] laminated carbon fiber reinforced aluminum honeycomb sandwich composites. The brittle fracture was observed in [0/90] laminated carbon fiber reinforced aluminum honeycomb sandwich composites. It was investigated that $[ \pm 45]$ laminated carbon fiber reinforced aluminum honeycomb sandwich composites showed more ductile fracture and greater impact absorption than others [28]. Sun et al. (2017) investigated the crashworthiness (strength of crash protection) of aluminum honeycomb sandwich panels which have the different thickness face sheets, cores and core sizes by performing three-point bending and in-panel compression tests. They found that the parameters of face sheets and honeycomb cores were important for obtaining peak load and energy absorption at the end of three-point bending test. In order to determine the specific energy absorption, it was observed that the thickness of face sheet wasn't effective parameter but honeycomb core parameters like that core sizes and thickness were so efficient [1]. Balaji and Annamalai (2018) applied to axial static low speed compressive tests to specimens of square, hollow aluminum column, aluminum honeycomb filled column and aluminum column and carbon fiber and aluminum honeycomb core filled aluminum columns. They defined that the square aluminum column filled with carbon fibre reinforced cylinder and a hexagonal aluminum honeycomb evidenced as the best specimen showed the best axial crashworthiness [29]. Patil et. al. (2017) investigated the reason of increase of $40 \%$ at impact absorption energy by changing cell configuration of aluminum honeycomb sandwich structures [30]. Shi et. al. (2014) studied to the toughness of interfaces of aluminum honeycomb core and face sheet composites with different core configuration. They expressed that the toughness of interfaces played an impressive role to increase the rigidity and strength of sandwich composites [31]. Jan et al. (2015) determined the bending strength and rigidity of glass fiber reinforced laminated aluminum core sandwich composites. They have determined the effect of aluminum core on deformation occurring under loads [11]. Hino et. al. (2010) examined the deformity characteristics of buckling deformations and differing sizes of cells by applying three-point bending tests to aluminum face sheets aluminum honeycomb sandwiches. In their studies, while researchers focused on the mechanical properties of different aluminum core size configurations and fiber reinforcement types of face sheets, the effects of crash worthiness and energy absorption and the occurred damages, the effects of the interface between the face plates and the aluminum core on mechanical and energy absorption were not considered [32]. Shi et al. (2014) tried to increase the interfacial toughness between the carbon fiber reinforced composite face sheets and aluminum honeycomb core by filling the short Kevlarfibers into the epoxy resin as adhesive. They determined that short kevlar fibers in epoxy resin which is adhesive provided to create a bridging effect on the interfaces between carbon fiber reinforced composite face sheets and aluminum core by raising the contact adhesion contact areas. They found that the bridging effect of short Kevlar fibers provided to increase of $14 \%$ three point bending peak loads and 61\% impact energy absorption [26]. Chen et. al. (2017) studied the effects of MWCNTs (Multiwall Carbon Nanotubes) on the adhesion strength of interface of carbon fiber reinforced composite face sheet and nomex honeycomb core. They found the increase of $12.9 \%$ in bending strength, $36 \%$ and $94.6 \%$ in peel load and peel energy release rate respectively by filling $1.5 \%$ wt. of MWCNTs. It was considered in their paper that MWCNTs occurred the bridging effects front of crack tips and changed the crack paths by blocking and so MWCNTs improved the mechanical properties of sandwich composites [35]. Vettorello et al. (2020) investigated the impact behaviors and attenuator of Formula SAE (FSAE) prototype vehicle as given in Figure 2. They focused on different FSAE attenuator design with four layers of aluminum honeycomb by applying numerical and experimental analysis for the design of a frontal passive safety system. They found that their hybrid model which consists of a simple 
honeycomb crash-box showed the highest crash energy absorption [39]. Castro et. al. (2020) studied the impact attenuator for the Formula racing car in order to decreasing weight and increase the crash impact safety which is providing the high impact energy absorption of impact attenuator in the University of Lisbon. They designed the impact attenuator sometimes called as crash box by using the aluminum honeycomb as an out-of-shelf solution. They applied by Abaqus software in order to optimize the designation. They defined that the aluminum honeycomb solution compares to the other aluminum structure and composites gave a fine solution to get highest crash impact energy absorption about with $60 \%$ mass reduction. As a shell of impact attenuator Carbon fiber/epoxy composite solution with $0^{\circ}$ ply orientation showed the highest energy absorption and $30^{\circ}$ ply orientation second higher energy absorption. In addition, this angle orientation of carbon fiber for composite shell of attenuator gained the $14 \%$ mass reduction. They especially determined that the geometric design of attenuator could provide the mass reduction at the range of $14 \%-28 \%$ by protecting the crash safety [40].

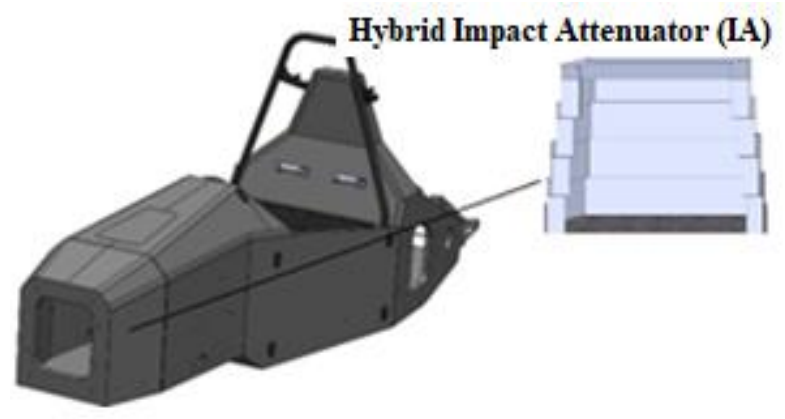

Figure 3. Isometric view of the FSAE (Formula SAE) prototype chassis (M19-L MoRe Modena Racing Team) [39].

In this study, the usability of E-Glass fiber reinforced aluminum-honeycomb sandwich composites was experimentally investigated to increase crashworthiness resistance and impact energy absorption ability and to make the car lighter by using E-Glass fiber reinforced sandwich composites as a crash protection bar (Side impact bar) instead of steel or aluminum bars used in the car/automotive vehicle doors. A crash protection metal bar called as side impact bars used in in the car/automotive vehicle doors is supported at two points inside them. Therefore, the crash protection bars show the tree point bending behavior. And so it was considered that these bending behaviors reveal the unsteady impact behaviors on the crash protection bar. However, it is thought to add originality to the study due to the fact that EGlass fiber reinforced aluminum-honeycomb sandwich composites can allow supporting the honeycomb from its four sides, takes the shape of the metal sheet inside the door and ultralight weight.

It was aimed to decrease the failures occurred at the interfaces between E-Glass fiber reinforced composites and aluminum cores and increase the crash worthiness or strength of crash protection in order to provide safety of driver and passenger by filling MWCNTs (Multi Walled Carbon Nanotubes) into epoxy resin which is matrix material and adhesive in this study. It was thought that it could provide an another originality to the study by filling MWCNTs because they enable the increase of crash impact resistance by providing nanoscale facture mechanisms, improving the impact toughness and rising the contact areas in the interfaces stemming from their high specific surface areas. E-glass fiber reinforcement has been preferred to reduce costs in automotive vehicles. The three-point bending and Charpy impact tests were carried out MWCNTs filled and unfilled E-Glass fiber reinforced aluminum sandwich composite specimens in order to determine mechanical properties according to ASTM and ISO standards. As results of tests, maximum loads and displacements, energy absorptions and failures were compared to each other.

\section{Materials and Method 2.1 Materials}

It was preferred to use $\left[0 / 90^{\circ}\right]$ unidirectional 300 tex E-Glass fiber fabrics as a reinforcement material in the top and bottom composite face sheets of fiber-reinforced honeycomb composite sandwiches in order to achieve the required strength of crash protection/worthiness and to obtain low cost values for use in automotive vehicles. DGBEA (Bisphenol A) epoxy resin was used as a matrix material for E-Glass fiber reinforced composite face sheets and an adhesive material for 
bonding the interfaces between composite face sheet and honeycomb core.

As honeycomb core material, aluminum (Al 3003) is used because of its low cost and plastic behaviors which provide more absorption during crash impact. The cell hexagonal width, cell thickness and foil thickness of the aluminum core are given respectively as $10.4,13.3$ and $0.04 \mathrm{~mm}$. It was determined the 4 layers of $\left[0 / 90^{\circ}\right]$ unidirectional E-Glass fiber fabrics for each composite face sheets [21].

DGBEA (Bisphenol A) epoxy resin was modified by filling MWCNTs (Multi Wall Carbon Nanotubes) in order to improve the mechanical properties of top and bottom composite face sheets, the adhesion strength of interfaces between composite face sheets and aluminum core and the failure occurrences. MWCNTs supplied from Timesnano company have an average diameter of $30 \mathrm{~nm}$ and a length of $10-30 \mu \mathrm{m}$.

\subsection{Experimental Methods}

The weight ratio of MWCNTs was determined as $0.3 \%$ when it was taken in consideration the studies in the literature to modify the DGBEA epoxy resin (MGS L160), which is a matrix material, the contribution rate of MWCNTs was determined as $0.3 \%$ wt. In the first, $0.3 \%$ wt. MWCNTs was filled into epoxy resin and mechanical mixing was done for 10 minutes [41]. In the second, the ultrasonic mixture process was carried out the mixture of epoxy and MWCNTs by using probe ultrasonicator device (Bandelin HD 2200) for $15 \mathrm{~min}$ [41]. At the end of the ultrasonic process, the mixture was cooled to room temperature in order to fill the hardener (MGS H160). And then, the hardener (36 wt.) was added to the modified epoxy with MWCNTs and stirred by mechanical stirrer for $5 \mathrm{~min}$. MWCNT filled and unfilled epoxy resins have been made ready for wetting E-Glass fiber fabrics by hand-lay method and adhesive for the interfaces wetted composite fabric and aluminum core. 4 layers of E-Glass fabrics (400x400mm) for top composite face sheet and 4 layers of E-Glass fabrics $(400 \times 400 \mathrm{~mm})$ for bottom composite face sheet were wetted with MWCNTs filled and unfilled epoxy resin on the fireproof and non-stick film by using handlay method. Aluminum honeycomb core was placed on 4 layers of E-Glass fabrics wetted by MWCNTs filled epoxy resin. And then, 4 layers of E-Glass fabrics wetted by MWCNTs filled epoxy resin were placed on the same aluminum honeycomb core. This process was repeated for the production of unfilled E-Glass aluminum sandwich composites. As final production step, the combined the wetted Eglass fabrics and aluminum cores were placed on a plate mold of hot press. MWCNT filled and unfilled E-Glass reinforced aluminum honeycomb sandwich composites were produced by using hot press under 5 bar pressure at $90^{\circ} \mathrm{C}$ during 1 hour for pre-curing process and during 1 hour at $120^{\circ} \mathrm{C}$ for post curing. The production processes are given in Figure 4. MWCNTs filled and unfilled epoxy resin within E-Glass fiber fabrics also serve as an adhesive at interfaces between the composite sheets and honeycomb cores, when the E-glass fiber reinforced composite face sheets and aluminum cores combined with each other.

Three-point bending samples according to ASTM C 393/C393M-20 [42] standard and unnotched Charpy Impact samples according to ISO 179/2 [43] standard were produced from MWCNT filled and unfilled reinforced E-Glass reinforced aluminum sandwich composite samples (E-Glass/Aluminum Sandwich Composites). The dimensions of each sandwich composite samples are as follow: length $\mathrm{l}=200 \mathrm{~mm}$, width $\mathrm{w}=28 \mathrm{~mm}$ and thickness $\mathrm{t}=15.5 \mathrm{~mm}$ for three bending tests. The dimensions of each sample are as follow: length $1=80 \mathrm{~mm}$, width $\mathrm{w}=20 \mathrm{~mm}$ and thickness $\mathrm{t}=15.5 \mathrm{~mm}$ for Charpy impact tests. Three-point bending tests and Charpy impact tests were performed three times according to ASTM E1556-08 [44] (5mm/min cross speed) and ISO 179/2 [43] standards (Figure 5).

The results obtained from three-point bending test were used to calculate the mechanical features of sandwich composites including core shear stress (I), facing bending stress (II), (III), as given in ASTM C393/C393M [42] and ASTM D7250/D7250M [45] Eq.1, Eq.2 and Eq.3 [17] are given below. 


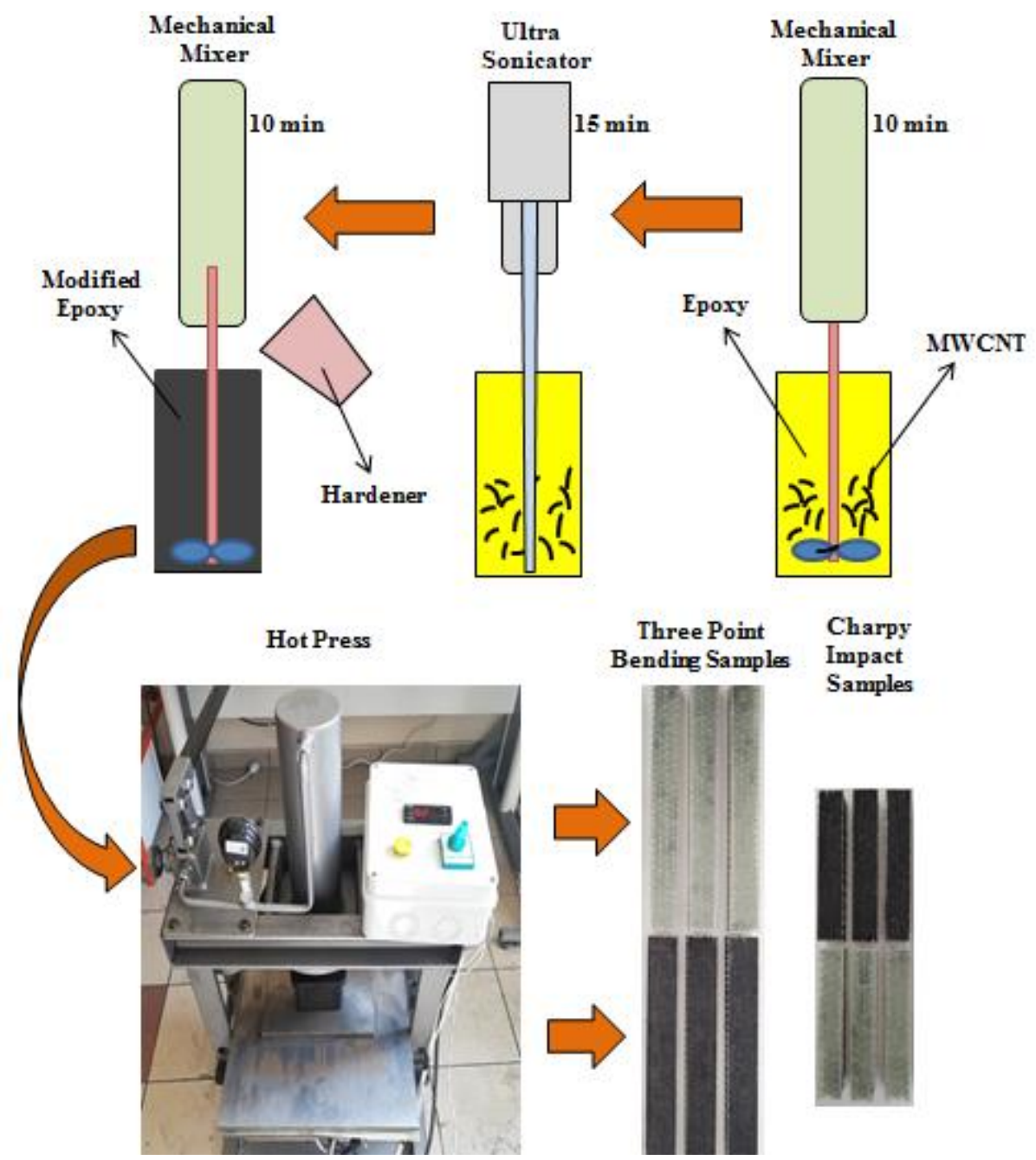

Figure 4. The processes of production.

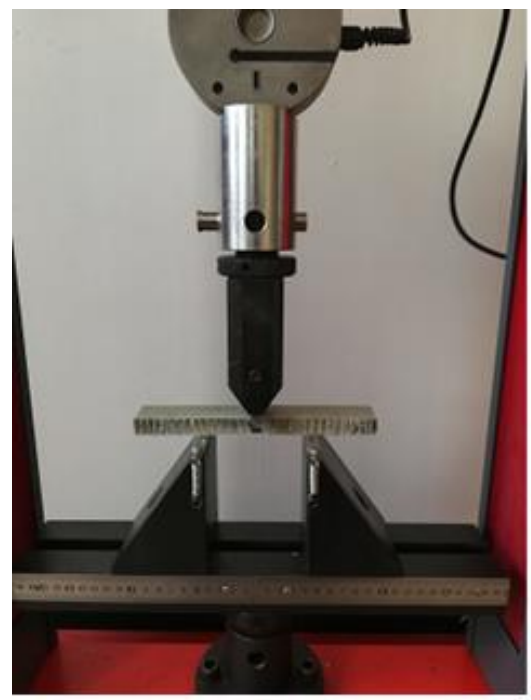

(a)

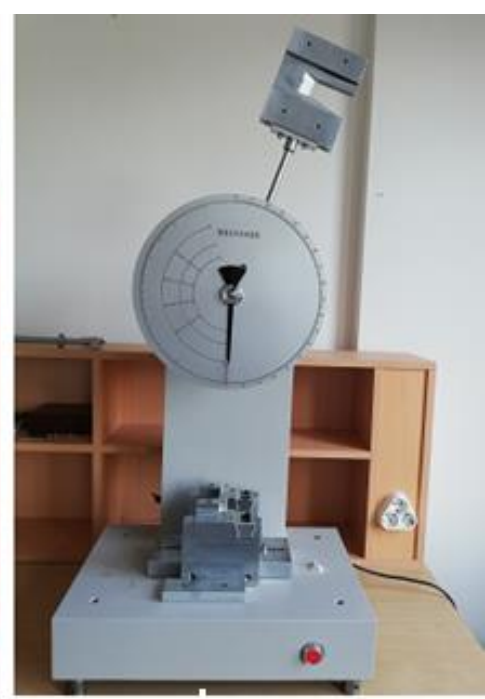

(b)

Figure 5. Three-point bending test (a) and Charpy impact tests of MWCNT filled and unfilled E-lass/Aluminum sandwich composite samples.

Core shear stress:

$F_{S}=\frac{P_{\max }}{(d+c) b}$

Where; $F_{S}=$ core shear stress $(\mathrm{MPa}), P_{\max }=$ maximum force $(\mathrm{N}), \mathrm{d}=$ sandwich thickness $(\mathrm{mm}), \mathrm{c}=$ core thickness $(\mathrm{mm}), \mathrm{b}=$ sandwich width $(\mathrm{mm})$. Facing bending stress:

$\sigma_{\text {facing }}=\frac{P_{\max } S}{2 t(d+c) b}$

Where; $\sigma_{\text {facing }}=$ facing bending stress $(\mathrm{MPa})$, $\mathrm{S}=$ support span length $(\mathrm{mm}), \mathrm{t}=$ facing 
thickness (mm). Bending Stress:

$\sigma_{\text {bending }}=\frac{3 P L}{2 b d^{2}}$

Where; $\sigma_{\text {bending }}=$ bending stress $(\mathrm{MPa}), \mathrm{F}=$ Force $(\mathrm{N})$

As a result of all tests, it is planned to replace E-Glass fiber reinforced aluminum honeycomb sandwich composites in cars as shown in Figure 11 as schematic view.

\section{Experimental Results}

MWCNTs filled and unfilled EGlass/Aluminum sandwich composite samples were produced according to ASTM C393/C393M-20 standard and three-point bending tests were performed to these samples according to ASTM E1556-08 standard. Threepoint bending tests were repeated three times for MWCNTs filled and unfilled EGlass/Aluminum honeycomb sandwich composite samples. The load-displacement graph and macro views of failures obtained as a result of three-point bending tests are presented in Figure 6. Figure 7(a) show the average maximum load graph of MWCNTs filled and unfilled E-Glass/Aluminum honeycomb sandwich composites. When Figure 6 were examined, it was clearly observed that the maximum load and maximum displacement values of MWCNT filled E-Glass/Aluminum honeycomb sandwich composites were quite high compared to unfilled E-Glass/Aluminum honeycomb sandwich composites. While the maximum bending load reached an average value of $862 \mathrm{~N}$ in MWCNTs filled GFR/Aluminum honeycomb sandwich composites, it reached an average value of $418.3 \mathrm{~N}$ [21] in unfilled GFR/Aluminum sandwich composites. When considering the average maximum bending load values in Figure 7(a), it was found that the MWCNTs additive increased the average maximum bending load value of GFR/Aluminum honeycomb composites by about 2.1 times. The average values of maximum bending displacements were $35.84 \mathrm{~mm}$ and $26.25 \mathrm{~mm}$ [21] for MWCNTs filled and unfilled GFR/Aluminum sandwich composites respectively (Figure7(b)). MWCNTs additive increased the average maximum bending displacement value of sandwich composites by about 1.36 times compared to unfilled sandwich composites. The values of average maximum load and displacement plots with standard deviations are given in Figure 6 and Figure 7. As shown in Figure 6, the curves of bending loads of MWCNT filled and unfilled E-Glass/Aluminum honeycomb sandwich composites have increased with a similar slope up to their maximum load values. However, a sudden vertical drop in load has seen at the curve of only unfilled E-Glass/Aluminum honeycomb sandwich composites after that maximum load (peak load). Following the applied load, the curve of load increase in unfilled honeycomb sandwich composite was again observed. And then, it was observed the sudden vertical drop in load. It was commented that the repeated sudden drop in loads for unfilled sandwich composites could be sign of slip-stick failure mechanism which occurs at interfaces between GFR composite sheets and aluminum honeycomb core as well as poor adhesion [26]. After the repeated sudden drop in load, load showed the slow decrease in load until the catastrophic failures. It was interpreted that the slow decrease in the curve of load for MWCNTs filled GFR/Aluminum honeycomb sandwich composite (Figure 6) might show the increase of adhesion at interfaces between GFR composite sheets and aluminum core, the limiting slit-stick failure mechanism and the occurrence plastic deformation in aluminum core as results of increasing load [35]. This phenomenon is clearly seen in Figure 6 which is graph with failures step by step.

When the Charpy impact energy absorptions were investigated in Figure 8 for un-notched all samples, the average values of impact energy absorption were 22.7J and 15.3J [21] for of MWCNTs filled and unfilled EGlass/Aluminum honeycomb sandwich composites respectively. It was seen that MWCNTs additive increased the average impact energy absorption of GFR/Aluminum sandwich composite by about 1.5 times. The impact energies absorbed by MWCNTs filled and unfilled E-Glass/Aluminum honeycomb composites are presented with their standard deviations in Figure 8. The values of bending stress, facing bending stress and core shear stress for all sandwich honeycomb composites are given in Table 1. according to Eq. 1, Eq. 2 and Eq. 3 [17]. 


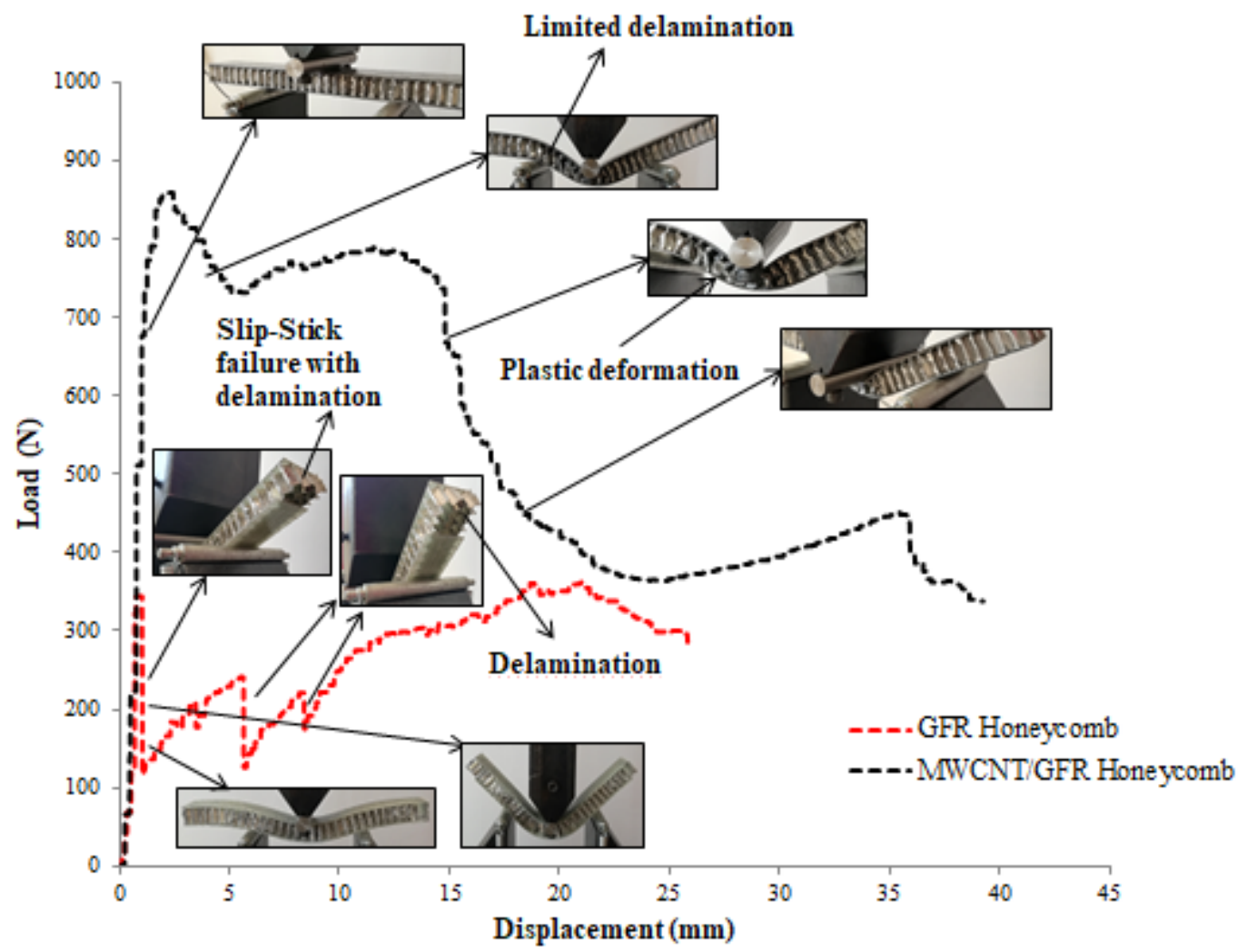

Figure 6. Load-Displacement of MWCNT filled and unfilled E-Glass/Aluminum honeycomb sandwich composites. GFR: Glass Fiber Reinforced MWCNT: Multi Walled Carbon Nanotubes

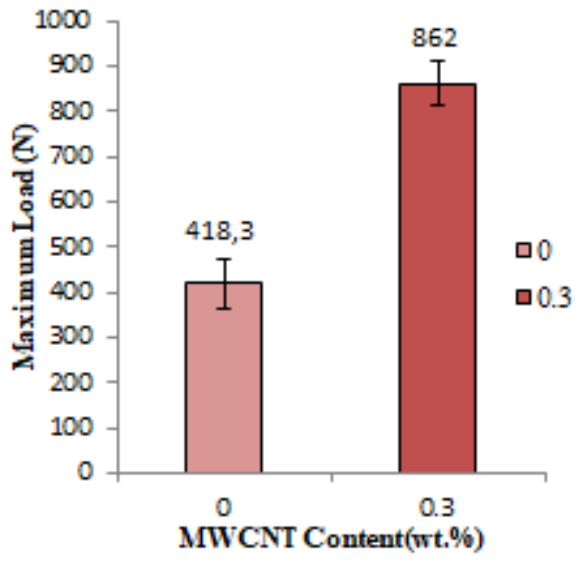

(a)

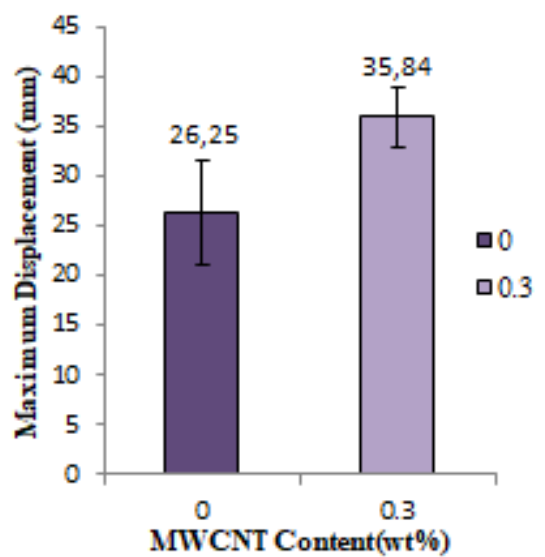

(b)

Figure 7. Maximum loads (a) and displacements (b) of MWCNTs filled and unfilled GFR/Aluminum honeycomb sandwich composites. GFR: Glass Fiber Reinforced MWCNT: Multi Walled Carbon Nanotubes

Table 1. Mechanical properties of MWCNTs filled and unfilled E-Glass/Aluminum honeycomb sandwich composites.

\begin{tabular}{cccccc}
\hline $\begin{array}{c}\text { Nano MWCNT } \\
\text { Content (\%wt.) }\end{array}$ & $\begin{array}{c}\text { Maximum Load } \\
(\mathrm{N})\end{array}$ & $\begin{array}{c}\text { Maximum } \\
\text { Displacement }(\mathrm{mm})\end{array}$ & $\begin{array}{c}\text { Bending } \\
\text { Stress (MPa) }\end{array}$ & $\begin{array}{c}\text { Facing Bending } \\
\text { Stress (MPa) }\end{array}$ & $\begin{array}{c}\text { Core Shear } \\
\text { Stress (MPa) }\end{array}$ \\
\hline 0 & $418.3 \pm 55$ & $26.25 \pm 5.2$ & $16.4 \pm 2.2$ & $19.2 \pm 2.5$ & $0.53 \pm 0.07$ \\
0.3 & $862 \pm 51.6$ & $35.84 \pm 3.1$ & $33.7 \pm 2$ & $39.7 \pm 2.4$ & $1.1 \pm 0.065$ \\
\hline
\end{tabular}

\section{Failure Analysis}

\subsection{Inspection of Microscope}

When the macro views of failures resulting from three-point bending test were investigated in Figure 6, it can be seen that the top face sheets are separated from the aluminum honeycomb core for unfilled EGlass/Aluminum honeycomb sandwich composites.

Interfacial delamination failures between the aluminum honeycomb core and the top laminated composite face sheet are clearly 


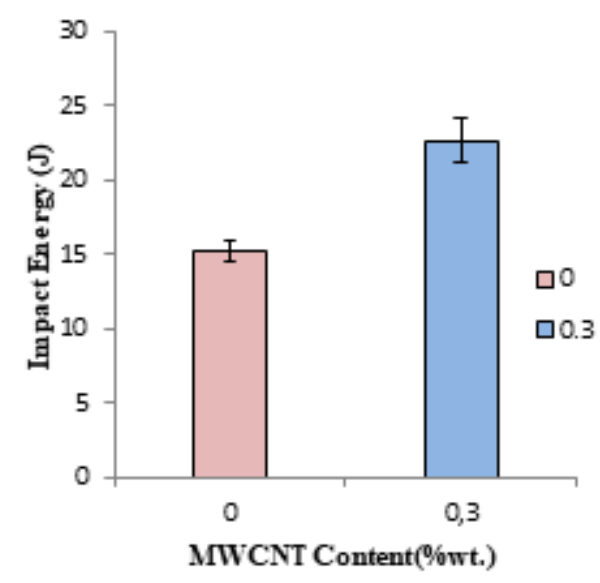

Figure 8. Impact energies of MWCNTs filled and unfilled E-Glass/Aluminum honeycomb sandwich composites. GFR: Glass Fiber Reinforced MWCNT: Multi Walled Carbon Nanotubes

observed in the microscope views of unfilled E-Glass/Aluminum honeycomb sandwich composites as shown in Figure 9(b) and Figure 9(c). Interfacial delamination failure between the aluminum honeycomb core and the upper surface composite layers is clearly observed in the microscope images of unfilled sandwich composites presented in Figure 9 (b) and Figure 9 (c). It also shows its marks in slipstick failure mechanism. The intensive failures of delamination and fiber breakages in E-glass fiber reinforced composite face sheet were detected on the microscope view as seen on Figure 9(a). Also in Figure 9(a), the failure of delamination was determined at the interface of aluminum honeycomb core and E-Glass composite top face sheet. The failure of delamination showing the separation of bottom E-Glass fiber reinforced composite face sheet from the aluminum honeycomb core is shown in Figure 9(d).

As the microscope views are carefully investigated in Figure 10, it is clearly seen that very important findings about the failures of MWCNTs filled GFR/Aluminum sandwich composites are obtained. First of all, when the failures of MWCNTs filled E-Glass top composite face sheet given in Figure 10(a) were examined as a result of the three-point bending test, it was seen that the failures of delamination and fiber breakage compared to unfilled E-Glass top composite face sheet are significantly reduced. It was found the limited local delamination at interfaces between top and bottom composite face sheets and aluminum core in Figure 10(b) and Figure 10(c). Whereas the dominant failure type was determined as delamination at interfaces between top and bottom composite face sheets and aluminum honeycomb core.

The top and bottom layers of E-Glass fabrics which were wetted by MWCNTs filled epoxy resin and unfilled epoxy resin were combined with aluminum honeycomb core and cured in hot press. Since the E-Glass fabrics are combined with aluminum honeycomb core as wetted with MWCNTs filled and unfilled epoxy resin, there was no need to apply external MWCNTs filled and unfilled epoxy adhesive on the interfaces. The wet resin which MWCNTs filled and unfiled epoxy in the laminated fabrics served as an adhesive for curing process of composite sheets and bonding the honeycomb core and composite sheets each other under the hot press. It was thought that these phenomena increased the structural integrity between top, bottom composite face sheets and honeycomb core in sandwich composite. It was commented that MWCNTs addition into epoxy resin for composite face sheets and interfaces increased the contact areas by occurring the fillet formation as given in Figure 10(b), Figure10(c) and Figure 10(d). In addition, it was considered that MWCNTs provided to increase the interfacial adhesion with the fillet formation which raises the interface areas of contact sides $[26,35]$. The obtained values of maximum loads, displacements and impact energies from test results are thought to prove these comments. It was seen that the delamination failures between composite face sheets and aluminum honeycomb core decreased considerably for MWCNTs filled 


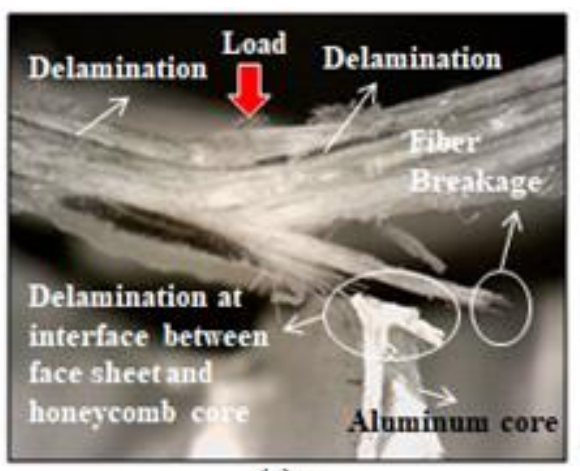

(a)

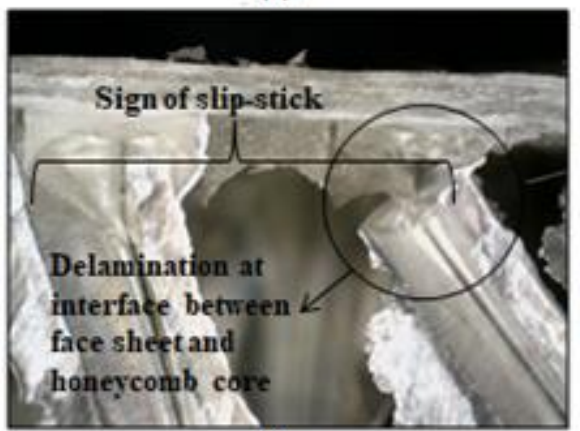

(c)

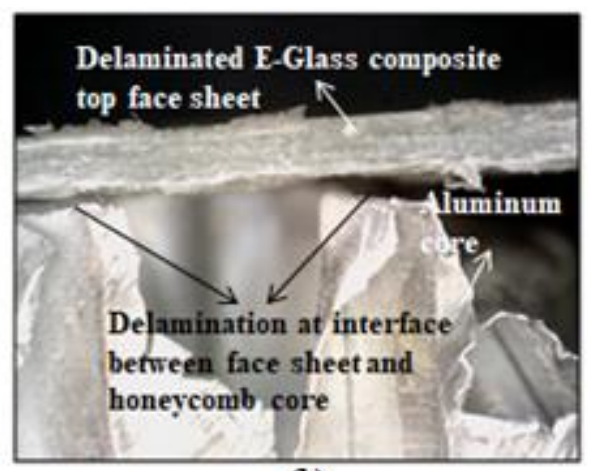

(b)

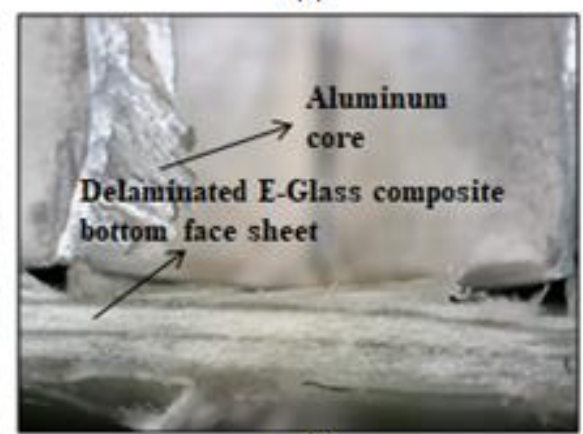

(d)

Figure 9. The failures of unfilled E-Glass/Aluminum honeycomb sandwich composites

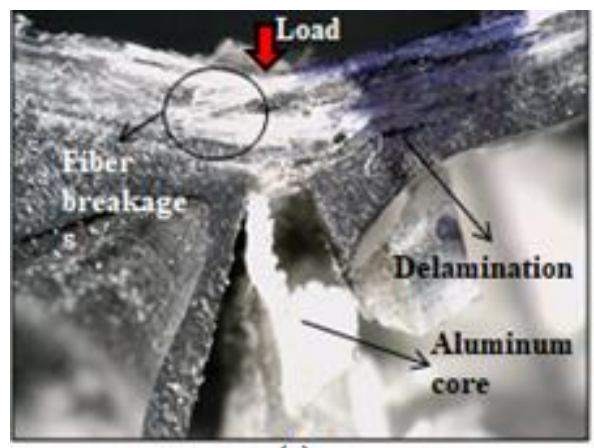

(a)

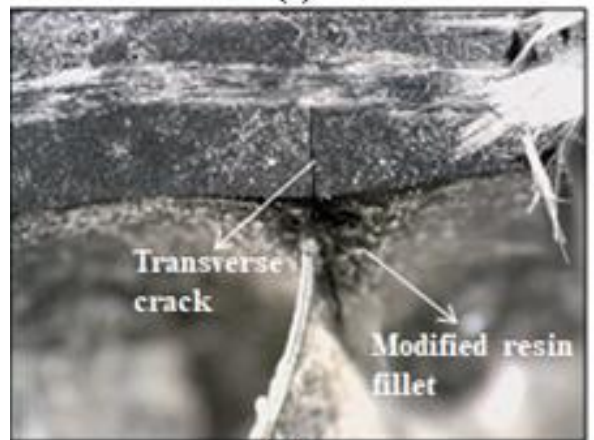

(c)

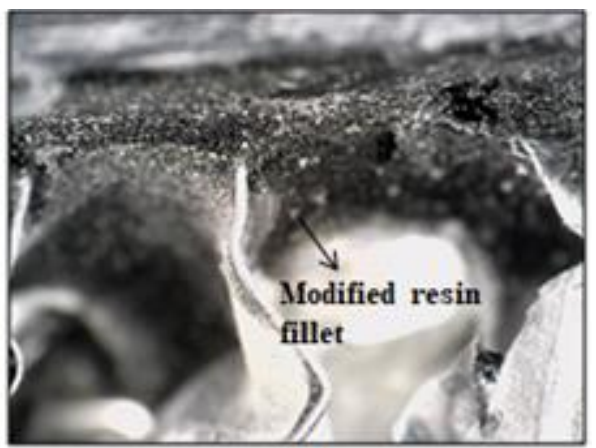

(b)

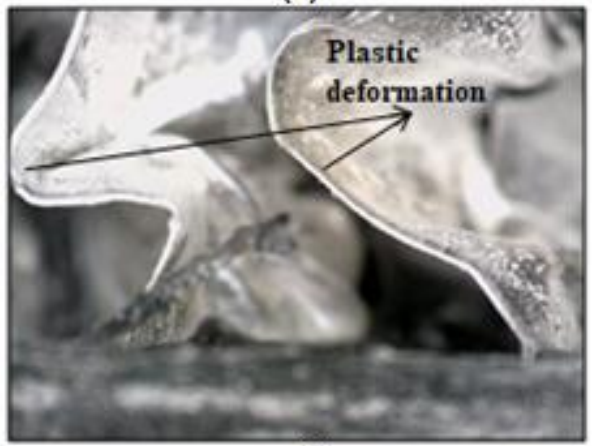

(d)

Figure 10. The failures of MWCNTs filled E-Glass/Aluminum honeycomb sandwich composites.

GFR/Aluminum sandwich composites, so the crashing of the aluminum honeycomb core increased as shown in Figure 10(d). At same time, the crushing in aluminum honeycomb core means the plastic deformation at aluminum honeycomb cell. It has been determined that plastic deformation caused by crushing in the aluminum honeycomb core is the dominant failure type for MWCNTs filled GFR/Aluminum honeycomb sandwich composite. Bending strength and energy absorption increased considerably as a result of plastic deformation failure. The increasing impact energy as a conclusion of the plastic deformation which occurred in MWCNTs filled GFR/Aluminum honeycomb sandwich 


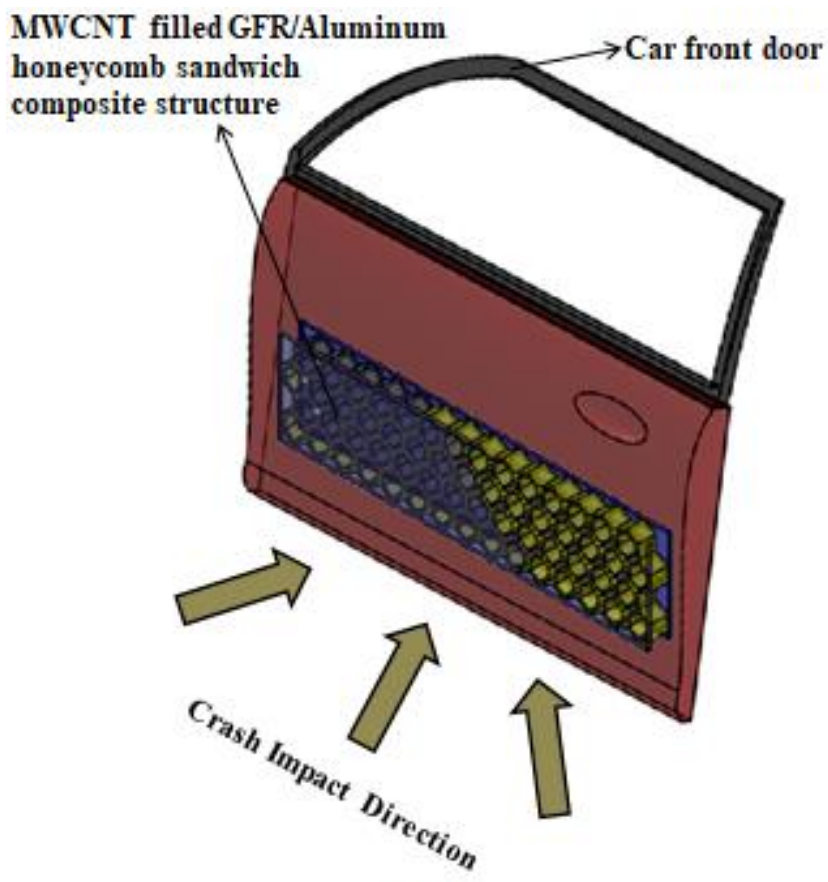

(a)

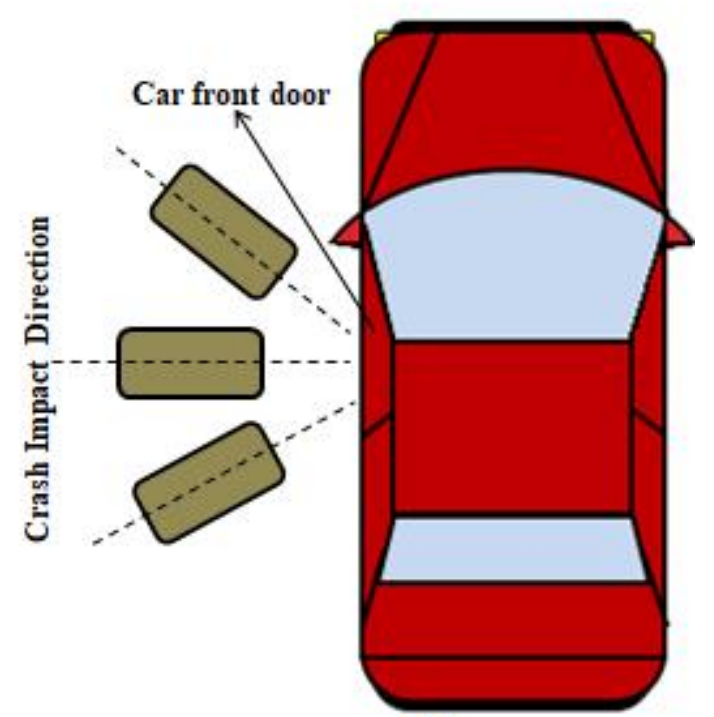

(b)

Figure 11. The possibility of schematic illustration of MWCNTs filled/Aluminum honeycomb composite structure montaged to car door (a), and the possibility of crash impact direction (b)

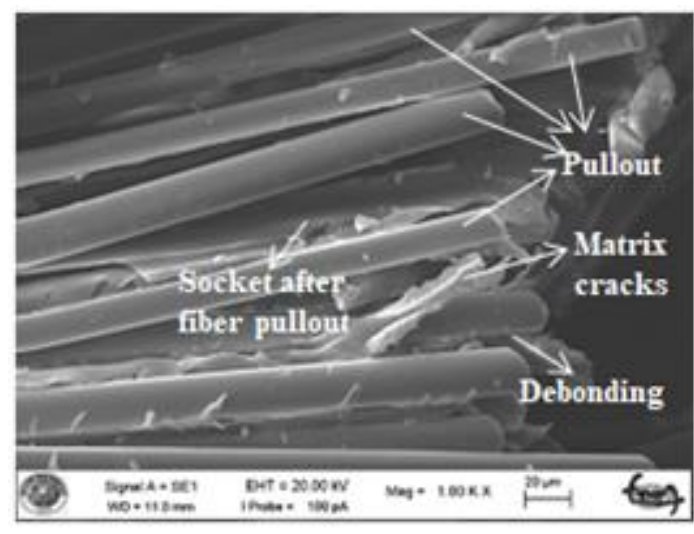

(a)

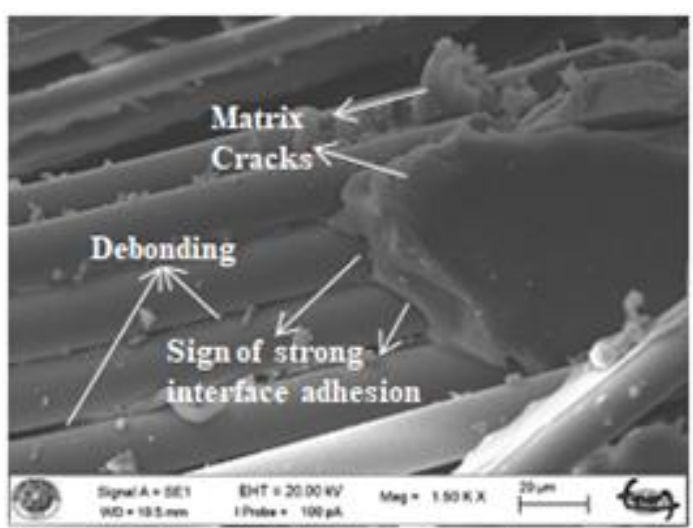

(b)

Figure 12. Failures of unfilled (a) and MWCNT filled (b) GFR/Aluminum honeycomb sandwich composites in SEM Analysis.

composite will increase the impact resistance of automotive vehicle doors during accident. In other words, it will increase the crashworthiness of automotive vehicle doors. As in the schematic illustrations given in Figure 11(a) and Figure 11(b), it is thought that the impact energy absorption can be similar in MWCNTs filled GFR/Aluminum sandwich composites regardless of the crash direction. It was considered that this is important approach for MWCNTs filled GFR/Aluminum sandwich composites instead of metal crash protect bar (Side impact bars) in automotive vehicle doors. Because the metal protection bar fixes it in the automotive vehicle door from two supports and so exhibits three-point bending behavior during crash impact. On the other hand, due to the fact that GFR/Aluminum sandwich composites improved by nanoparticles can be supported on many places in the car doors, it is thought that the impact behaviors may display similar during the crash impacts. Therefore, it is interpreted that it will create better impact resistance than traditional automotive door protects bars. SEM views given in Figure 12 support microscope images and comments. When the SEM views given in Figure 12 (a) and Figure 12 (b) were observed, micro-scale failures of unfilled and MWCNTs filled Glass fiber reinforced top face composite sheet can be clearly seen. The failures of debonding, pullout and socket after pullout 
given in Figure 12(a) were observed intensely for unfilled GFR/Aluminum honeycomb sandwich composites as a result of the bending load. At the same time, matrix cracks were observed in the SEM view in Figure 12(a). Another important situation for unfilled GFR/Aluminum sandwich composite is that the fiber surfaces are quite smooth and the adhered matrix is very low. This situation was considered to be sign that the interfacial strength between fiber and matrix was weak for unfilled GFR/Aluminum sandwich composite [35-38]. In the SEM view of Figure 12(b), there are large amounts of epoxy particles adhered to the surfaces of E-Glass fibers. In addition, the failures of pull out are seen to be much less as shown in Figure 12(b). These phenomena exhibited that MWCNTs provided to increase the interfacial contact area and interfacial adhesion strength. The increasing impact energies (impact resistance) caused by MWCNTS additive has been supported these comments. Furthermore, MWCNTs addition into epoxy which serves as matrix and adhesive materials increased the interfacial contact areas by providing fillet formation at interfaces between composite face sheets and aluminum honeycomb core besides, it was significantly considered that the nano-scale fracture mechanisms improved the mechanical properties like face, bending, core shear stress, maximum bending load and displacement and impact absorption energies [35]. These nanoscale fracture mechanisms according to review of literature are bridging of cracks, blunting and blocking front of cracks and crack branching by providing the occurrence of secondary cracks [33 - 38]. Moreover, it was figured out that the increase of ductility and fracture toughness caused by MWCNTs addition into epoxy matrix and adhesive material played the efficient role to reduce the occurrence of failures and restrain the slip-stick failures as another outstanding factor $[26,35]$.

\section{Conclusion}

Automotive vehicles need to be lightened to save fuel for gasoline/diesel vehicles and increase battery distance range for electric vehicles. While the automotive vehicles are lighting, the increasing automotive crashworthiness or crash avoidance and safety should be ensured. In this study, it was investigated to use the fiber reinforced honeycomb sandwich composite structures instead of the metals protection bar for automotive vehicle doors by utilizing the usage of nanocomposite technology to lighten the automotive vehicles and improve their safety. The three-point bending and Charpy impact in terms of ASTM standards tests have been applied to the multi walled carbon nanotubes (MWCNTs) filled and unfilled GFR/Aluminum honeycomb sandwich composites in order to represent the failures that occurred during car accident. The failures were commented with SEM analysis and microscope views. The results of tests and commentaries are summarized as follow.

- As a result of three-point bending tests, the addition of $0.3 \%$ MWCNTs increased the average maximum bending load of GFR/Aluminum honeycomb sandwich composites by about 2.1 times compared to unfilled GFR/Aluminum honeycomb sandwich composites.

- The addition of MWCNTs increased the average maximum bending displacement of GFR/Aluminum honeycomb sandwich composites by about 1.36 times. It was considered that the increasing displacements as conclusion of the MWCNTs addition improved the fracture toughness in top and bottom laminated composite face sheets and interfaces between composite face sheets and aluminum core.

- It was found that the addition of $0.3 \%$ MWCNTs increased the average impact energy absorption of GFR/Aluminum honeycomb sandwich composites by about 1.5 times compared to unfilled GFR/Aluminum honeycomb sandwich composites as a result of Charpy impact tests for un-notched all samples.

- The intensive delamination and fiber breakage failures were observed in unfilled GFR composite top and bottom face sheets. Furthermore, the accumulated delamination failure was detected at interfaces between top and bottom composite sheets and aluminum honeycomb core.

- It was also found that the top composite face sheets of some unfilled GFR/Aluminum honeycomb sandwich composite samples were completely separated from aluminum 
honeycomb cores. It was determined that the dominant failure type was delamination. In addition, slip-stick failure mechanism has been observed at interfaces between unfilled GFR composite top face sheet and aluminum honeycomb core during the bending load.

- It was found in that the delamination failures were restricted in both GFR laminated composite top face sheets and interfaces between composite top face sheets and honeycomb core by filling MWCNTs. The dominant failure type was determined as the plastic deformation failures in aluminum honeycomb core cells.

- It was observed that MWCNTs provided the fillet formation at interfaces by increasing interface areas. Fillet formation is thought to contribute to the increase of the interfacial strength. It was commented that the fracture toughness mechanisms by provided MWCNTs increased the crashworthiness and impact protection resistance.

- As a result of the obtained findings it was considered that MWCNTs filled GFR/Aluminum honeycomb sandwich composites instead of metal protection bars can be used due to their high crashworthiness/impact resistance and energy absorption at every point of the car doors protection bars, and their ultra-light weight and the possibility mounted to more areas in car doors.

When taken into consideration the nanocomposite technology for automotive vehicles, it was commented that MWCNTs (Multi Walled Carbon Nanotubes) increased the crashworthiness and impact resistance (high impact energy absorption) of GFR/Aluminum honeycomb sandwich composites and restricted the failure propagations of them.

\section{Acknowledgement}

In this study, SEM analyses were supported by the Selçuk University Scientific Research Projects (B.A.P) under grant number 17601070.

\section{References}

1. Sun G., Huo X., Chen D., Li Q., "Experimental and numerical study on honeycomb sandwich panels under bending and in-panel compression", Materials and
Design, 133, 154-168, 2017.

2. $\quad \mathrm{Xu}$ J., Wu Y., Wang L., Li J., Yang Y., Tian Y., Gong Z., Zhang P., Nutt S., Yin S., "Compressive properties of hollow lattice truss reinforced honeycombs (Honeytubes) by additive manufacturing: Patterning and tube alignment effects", Materials and Design, 156, 246-257, 2018.

3. Altın M., "Effect of taper angle on crashworthiness performance in hybrid tubes", International Journal of Automotive Engineering and Technologies, 9(1), 11-19, 2020.

4. Wang J., Chengyang Shi C., Yang N., Sun H., Liu Y., Song B., "Strength, stiffness, and panel peeling strength of carbon fiberreinforced composite sandwich structures with aluminum honeycomb cores for vehicle body", Composite Structures, 184, 1189-1196, 2018.

5. Feng L-J., Yang Z-T., Yu G-C, Chen XJ., Lin-Zhi Wu L-Z., "Compressive and shear properties of carbon fiber composite square honeycombs with optimized high-modulus hierarchical phases", Composite Structures, 201, 845-856, 2018.

6. Crupi V., Epasto G., Guglielmino E., "Comparison of aluminum sandwiches for lightweight ship structures: Honeycomb vs. foam" Marine Structures, 30, 74-96, 2013.

7. Zhou X.Q., Wang L., Yu D.Y., Zhang C.Y., "Dynamic effective equivalent stiffness analysis on the periodical honeycomb reinforced composite laminated structure filled with viscoelastic damping material", Composite Structures, 193, 306-320, 2018.

8. Chen D.H., Masuda K., "Effects of honeycomb geometry on stress concentration due to defects" Composite Structures, 188, 5563, 2018.

9. Eloy F. S., Gomes G. F., Ancelotti Jr. A. C., Cunha Jr. S. S., Bombard A. J. F., Cunha Jr. S. S., Bombard A. J. F., Junqueira D. M., "Experimental dynamic analysis of composite sandwich beams with magnetorheological honeycomb core" Engineering Structures, 176, 231-242, 176, 2018.

10. Belingardi G., Martella P., Peroni L., "Fatigue analysis of honeycomb-composite sandwich beams "Composites: Part A 38 11831191, 2007.

11. Jan S., Khan R. U., Ahmad S., Amjad M., Badshah S., Ahmad M., "Flexural strength 
of honey comb sandwich structures", Int. Journal of Applied Sciences and Engineering Research, 4(1), 86-93, 2015.

12. Li X.,, Lu Z., Yang Z., Yang C.,"Anisotropic in-plane mechanical behavior of square honeycombs under off-axis loading" Materials and Design, 158, 88-97, 2018.

13. Zhao L., Zheng Q., Fan H., Jin F., "Hierarchical composite honeycombs" Materials and Design, 40, 124-129, 2012.

14. Xie W.H., Meng S.H., Ding L., . Jin H., Du S.Y., Han G.K., Wang L.B., Xu C.H., Scarpa F., Chi R.Q., "High-temperature highvelocity impact on honeycomb sandwich panels" Composites Part B 138, 1-11, 2018.

15. Sikdar S, Banerjee S., "Identification of disbond and high density core region in a honeycomb composite sandwich structure using ultrasonic guided waves", 152, 568-578, 2016.

16. Girolamo D., Chang H-Y., Yuan F-G, "Impact damage visualization in a honeycomb composite panel through laser inspection using zero-lag cross-correlation imaging condition" Ultrasonics, 87, 152-165, 2018.

17. Farooq U., Ahmad M.S., Rakha S.A., Ali N., Khurram A. A., Subhani T., "Interfacial Mechanical Performance of Composite Honeycomb Sandwich Panels for Aerospace Applications", Arab J Sci Eng., 42, 1775$1782,2017$.

18. Li G., Fang Y., Hao P., Li Z., "Threepoint bending deflection and failure mechanism map of sandwich beams with second-order hierarchical corrugated truss core", Journal of Sandwich Structures and Materials, 19(1), 83107, 2017.

19. Zhang Y., Zong Z., Liu Q., Ma J., Wu Y.,Li Q.," Static and dynamic crushing responses of CFRP sandwich panels filled with different reinforced materials", Materials and Design, 117, 396-408, 2017.

20. Gholami M., Alashti R.A., Fathi A., "Optimal design of a honeycomb core composite sandwich panel using evolutionary optimization algorithms", Composite Structures, 139, 254-262, 2016.

21. Demirci M.T., "Investigation of glass fiber reinforced aluminum honeycomb sandwich composites", International congress of science culture and education (INCES 2019), 300-305, Antalya, 29 Oct-02Nov-2019.
22. Demirci M.T., Dönmez O., Devrez Ş., Demirci İ., "Investigation of mechanical behaviors of carbon fiber reinforced aluminum honeycomb", IV International academic research congress, 30 Oct.-03 Nov. Alanya, Turkey, 2018.

23. Demirci M.T., "Impact behaviors of basalt fiber reinforced honeycomb epoxy composites", 7th International Conference ICAT'18, April 28 - May 1, pp. 979-981, Antalya, Turkey, 2018.

24. Lu C., Zhao M.,Jie L.,Wang J., Gao y., Cui X., Chen P., "Stress Distribution on Composite Honeycomb Sandwich Structure Suffered from Bending Load", Procedia Engineering, 99, 405 - 412, 2015.

25. Ashab ASM., Ruan D., Lu G., Wong Y.C., "Quasi-static and dynamic experiments of aluminum honeycombs under combined compression-shear loading", Materials and Design, 97, 183-194, 2016.

26. Shi S-S., Sun Z., Hu X-Z., Chen H.R.," Carbon-fiber and aluminum-honeycomb sandwich composites with and without Kevlarfiber interfacial toughening", Composites: Part A, 67, 102-110, 2014.

27. Mohamed M., Anandan S., Huo Z., Birman V., Volz J.,Chandrashekhara K.," Manufacturing and characterization of polyurethane based sandwich composite structures" Composite Structures, 123 169179, 2015.

28. Flasar O., Triska V., Junas M.," Experimental study of impact properties of aluminium honeycomb sandwich structure" MATEC Web of Conferences 133, 1-5, 2017.

29. Balaji G., Annamalai K.," Crushing response of square aluminum column filled with carbon fibre tubes and aluminum honeycomb" Thin-Walled Structures, 132, 667-681,2018.

30. Patil R. V., Lande P. R., Tadamalle A.P., Reddy Dr. Y. P.," Determination of Impact Absorbing Capacity and toughness of Aluminum Honeycomb Sandwich Panel in Bumper Beam" Materials Today: Proceedings, 4 8816-8826, 2017.

31. Shi S., Sun Z., Hu X., Chen H.," Flexural strength and energy absorption of carbon-fiber-aluminum honeycomb composite sandwich reinforced by aluminum grid", ThinWalled Structures $84,416-422,2014$. 
32. Hino H., Takayama Y., Kato H., Watanabe H., "Deformation Behavior in Threepoint Bending of Aluminum Alloy Honeycomb Structures" Proceedings of the 12th International Conference on Aluminium Alloys, September 5-9, 625-630,Yokohama, Japan, 2010.

33. Wang P., Zhang X., Lim G., Neo H., Malcolm A. A., Xiang Y., Lu G., Yang J.," Improvement of impact-resistant property of glass fiber-reinforced composites by carbon nanotube-modified epoxy and pre-stretched fiber fabrics", Journal of Materials Science, 50, 5978-5992, 2015.

34. Rathore, D. K., Prusty R. K., Kumar D. S., Ray B. C., "Mechanical performance of CNT-filled glass fiber/epoxy composite in insitu elevated temperature environments emphasizing the role of CNT content", Composites Part A: Applied Science and Manufacturing, 84, 364-376, 2016.

35. Chen C., Li Y., Gu Y., Li M., Zhang Z., "Effect of MWCNTs added by electrostatic flocking method on adhesion of carbon fiber prepreg/Nomex honeycomb sandwich composites", Materials \& Design, 127, 15-21, 2017.

36. Demirci İ., "Impact behaviors of carbon nanotubes and nano silica reinforced basalt/epoxy hybrid nanocomposites in corrosion environment", The Graduate School of Natural and Applied Science of Selçuk University, The Degree of Master of Science in Mechanical Engineering, 1-104, 2017.

37. Taraghi I., Fereidoon A., TaheriBehrooz F., "Low-velocity impact response of woven Kevlar/epoxy laminated composites reinforced with multi-walled carbon nanotubes at ambient and low temperatures", Materials \& Design, 53, 152-8, 2014.

38. Tehrani M., Boroujeni A., Hartman T., Haugh T., Case S., Al-Haik M., "Mechanical characterization and impact damage assessment of a woven carbon fiber reinforced carbon nanotube-epoxy composite", Composites Science and Technology, 75, 42-8, 2013.

39. Vettorello A., Campo G. A., Goldoni G., Giacalone M., "Numerical-Experimental Correlation of Dynamic Test of a Honeycomb Impact Attenuator for a Formula SAE Vehicle", Metals 10 (652), 1-22, 2020.

40. Castro J.M.P.B. C., Fontana M., Araujo
A. L., Madeira J.F.A." Optimization of a composite impact attenuator for a formula student car" Mechanics of Advanced Materials And Structures, 1-11, 2020.

41. Demirci M.T., Tarakçıoglu N., Avcı A., Akdemir A., Demirci I., "Fracture toughness (Mode I) characterization of $\mathrm{SiO}_{2}$ nanoparticle filled basalt/epoxy filament wound composite ring with split-disk test method" Composites Part B, 119, 114-124, 2017.

42. ASTM C393/C393M-20, "Standard Test Method for Core Shear Properties of Sandwich Constructions by Beam Flexure", ASTM International, West Conshohocken, PA, 2020, www.astm.org.

43. ISO 179/2:2020, "PlasticsDetermination of Charpy impact PropertiesPart 2: Instrumented impact test", 2020, www.iso.org.

44. ASTM E1556-08, "Standard Specification for Epoxy Resin System for Composite Skin, Honeycomb Sandwich Panel Repair", ASTM International, West Conshohocken, PA, 2008, www.astm.org.

45. ASTM D7250/D7250M-20, "Standard Practice for Determining Sandwich Beam Flexural and Shear Stiffness", ASTM International, West Conshohocken, PA, 2020, www.astm.org. 